\title{
EXPECTATIVAS PRÉVIAS AO IMPLANTE COCLEAR E AVALIAÇÃO PÓS IMPLANTE EM ADOLESCENTES*
}

\author{
PREVIOUS EXPECTATIONS CONCERNING \\ COCHLEAR IMPLANT AND POST IMPLANT EVALUATION \\ IN ADOLESCENTS
}

\author{
Gisele Aparecida de Oliveira MURAKAMI' \\ Carmen Maria Bueno NEME² \\ Midori Otake YAMADA ${ }^{3}$ \\ Maria Cecília BEVILACQUA ${ }^{4}$
}

\begin{abstract}
RESUMO
O trabalho objetivou verificar tendências de relação entre expectativas prévias (E.P.), ansiedades e temores de pacientes candidatos a Implante Coclear (I.C.) e suas avaliações posteriores quanto a ganhos obtidos com o implante. Os sujeitos foram 6 pacientes, de ambos os sexos, entre 13 a 19 anos de idade com I.C. realizado de 7 a 44 meses. Dados anteriores à cirurgia foram coletados dos prontuários e comparados aos coletados via entrevista semi-estruturada na fase de reabilitação posterior. Resultados indicaram similaridade entre tipos de E.P. e avaliações subseqüentes ao I.C.. O aspecto estético mostrou-se importante fator de preocupação. A orientação pré-cirúrgica facilitou adequação de E.P. e avaliações de ganhos pós implante. Indica-se a necessidade de acompanhamento psicológico pré e pós I.C. para minimizar dificuldades
\end{abstract}

(") Trabalho realizado no período em que a autora era aluna do curso de Especialização em Psicologia Clínica na Universidade de São Paulo - USP - Bauru. A autora é grata à Professora Mestre Carmen Maria Bueno Neme pelo profissionalismo e empenho dispensados às orientações e sugestões essenciais à realização deste trabalho também agradece à disponibilidade e atenção de Midori Otake Yamada como co-orientadora e da Dra. Maria Célia Bevilacqua.

(1) Psicóloga, especializanda do curso de Especialização em Psicologia Clínica do Hospital de Reabilitação de Anomalias Craniofaciais - HRAC-USP/Bauru-SP

Endereço para correspondência: Dr. Sérvio Túlio Carrijo Coube 3-33 Apto. 81A - Infante Dom Henrique / CEP 17.011-490 Bauru-SP

(2) Doutora em Psic. Clínica. Universidade Estadual Paulista - Bauru e orientadora do curso Especialização em Psicologia Clínica do HRAC-USP/Bauru-SP

(3) Psicóloga do Hospital Reabilitação de Anomalias Craniofaciais e mestranda do Progr. de Pós-graduação em Dist. da Comunicação Humana HRAC-USP/Bauru-SP

(4) Prof. Doutora Curso de Fonoaudiologia da Fac. Odontologia de Bauru-USP. Fonoaudióloga do CPA HRAC-USP/ Bauru. Prof. Titular do Programa de Pós-graduação em Distúrbios da Comunicação da PUC-SP. 
de adaptação relacionadas à auto-imagem de pacientes adolescentes e adequação de expectativas.

Palavras-chave: Expectativas Prévias, Implante Coclear, Adolescente, Auto Imagem.

\begin{abstract}
This work aimed to verify tendencies of relation between previous expectations (P.E.), anxieties and fears of patients applying to Cochlear Implant (C.I.) and their later evaluation concerning the gains obtained with the implant. The subjects were 6 patients of both sexes, between 13 and 19 years of age, with C.I. accomplished from 7 to 44 months. The data previous to the surgery were collected from the patients registers and compared with the ones collected through the semi-structured interview conducted during the later rehabilitation stage. The results indicated similarity between two kinds of P.E. and evaluation post C.I.. The aesthetic aspect revealed itself as an important factor among the patients concerns. The pre-surgery guidance made the P.E. more adequate as well as the evaluation of the gains post C.I.. The necessity of psychological attendance pre and post C.I. is indicated in order to minimize the difficulties of adaptation related to the self-image of adolescent patients and the development of proper expectations.
\end{abstract}

Key-words: Previous Expectations, Cochlear Implant, Adolescence, self-image.

\section{INTRODUÇÃO}

Atualmente o Implante Coclear é considerado um método de tratamento importante como também um empolgante avanço para auxiliar pacientes com perdas auditivas profundas. O Implante Coclear referese a um sistema eletrônico utilizado para promover estimulação auditiva e melhorar a comunicação dos deficientes auditivos profundos. O Implante Coclear é realizado por meio da implantação cirúrgica de uma antena receptora e de eletrodos dentro da cóclea para a estimulação direta do ouvido. "Este sistema é acrescido de uma parte externa que capta o som, por um microfone instalado junto à orelha, que é transmitido por um fio ao processador de fala. O processador envia a informação codificada para uma antena transmissora colocada junto ao receptor-estimulador. O ciclo da audição se completa quando o estímulo elétrico e os sinais codificados são transmitidos por rádio freqüência para o receptor transmissor. Este aparelho estimula os eletrodos que estão implantados na cóclea."(Yamada, Bevilacqua e Costa Filho 1999, p.1)

Segundo Costa Fillho \& Bevilacqua (1999), o Implante Coclear pode ser formado por 2 componentes: "Interno 1) receptor-estimulador (colocado cirurgicamente junto ao osso do crânio, atrás da orelha sob a pele); 2) cabo multicanal de eletrodos (instalado no interior do ouvido interno, na cóclea ou caracol). Externo A) processador de fala: com o tamanho de um aparelho de amplificação sonora convencional, pode ficar junto à cintura ou ao peito. Envia a informação codificada para a antena transmissora (Ver letra A, figura I), B) microfones e fios: instalado externamente junto à orelha para captar e transmitir o som 
para o processador de fala (Ver letra B, figura I); C) antena transmissora: fixada por um imã em um ponto da cabeça onde se encontra o receptor-estimulador do implante sob a pele (Ver letra C, figura I). O ciclo da audição se completa quando o estímulo elétrico e os sinais codificados são transmitidos por radiofreqüência para o receptor-transmissor. Este dispositivo, por meio dos eletrodos que estão implantados no interior da cóclea (caracol), estimula as terminações das fibras nervosas do nervo auditivo que envia para o cérebro os impulsos nervosos." (p. 3)

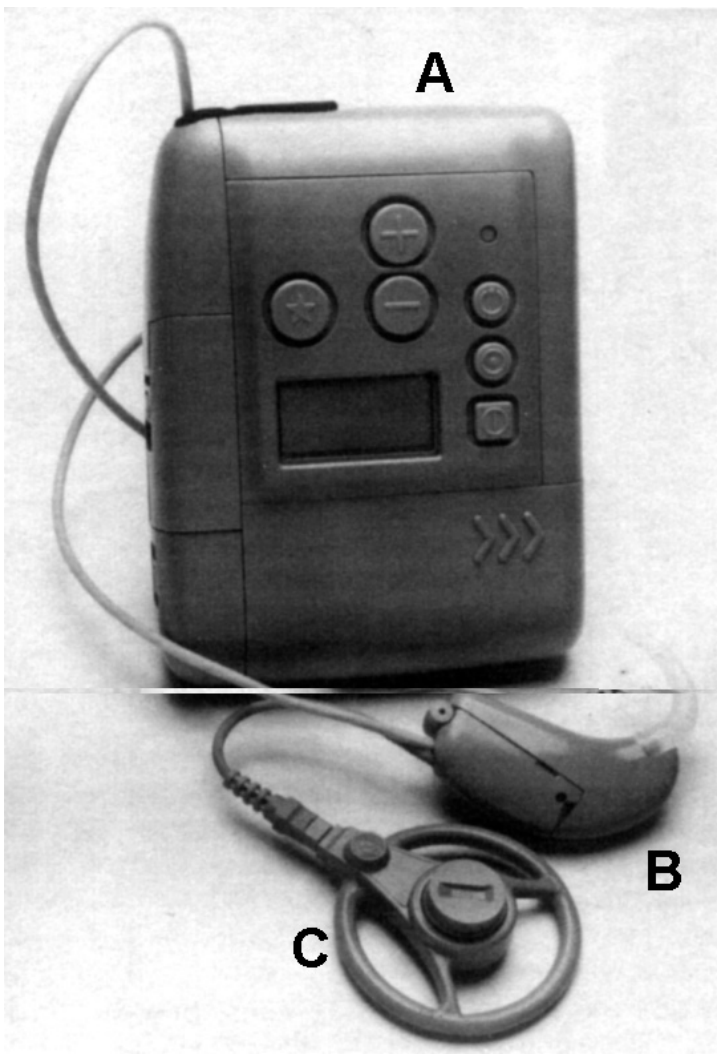

Figura 1. Componente externo do implante coclear multicanal (Nucleus 24). (Bevilacqua, 1998)

Dada a complexidade da cirurgia e adaptação ao Implante coclear em geral, os centros que realizam tal cirurgia, fazem uma seleção de candidatos ao Implante Coclear, de forma a garantir melhores resultados. Esta seleção é realizada por equipe interdisciplinar composta de: médicos (neurologista, otologista, otorrinolaringologista, pediatra), enfermeiros, fonoaudiólogos, assistente sociais e psicólogos. Cooper (1995), a respeito da seleção de candidatos ao Implante Coclear, relata: "Apenas um subconjunto de todas as pessoas profundamente ou totalmente surdas são candidatas adequadas para o Implante Coclear. A adequação é uma entidade complexa, porém, em suma, pode ser reduzida a seis principais áreas: 1) idade do paciente; 2) nível de audição; 3) sobrevivência do nervo auditivo; 4) tomografia computadorizada; 5) status psicológico; 6) aptidão médica.” (p.282). Geralmente, durante o processo de seleção para a cirurgia, os pacientes recebem orientações verbais da equipe além de informes escritos sobre a cirurgia, o pós operatório e a reabilitação do Implante Coclear. Em muitos casos, as informações verbais recebidas pelos pacientes candidatos à cirurgia são suficientes para adequar suas expectativas, fantasias, ansiedades, temores, angústias à realidade do Implante Coclear. Os aspectos emocionais envolvidos no processo de cirurgia e adaptação posteriores devem ser valorizados, sendo importante averiguar a existência de expectativas irrealistas, conforme indica Cavalcanti (1994). Expectativas e fantasias "irrealistas" podem comprometer o envolvimento do paciente e familiares em todo o processo de adequação e habilitação posterior ao implante. Neste sentido, Ribeiro (1995) assinala a importância em se ouvir o paciente, de modo a entender suas expectativas, avaliando se são realistas ou não em relação ao possível resultado cirúrgico. Cooper (1991) menciona que o paciente, indicado para o programa de Implante Coclear, deverá ser avaliado, pela equipe, nos aspectos psicológicos incluindo motivação, expectativas, estado emocional e aceitação de sua deficiência auditiva. Para Neme (1991): "A expectativa do paciente, ou o que o paciente está buscando, o que se espera conseguir com o tratamento realizado desta ou daquela 
maneira, é um aspecto reconhecido por qualquer clínico experiente." (p.46).

Dada a importância de se avaliar tais condições psico-sociais que incluem expectativas, motivação dentre outros aspectos, é imprescindível que especial atenção seja dada para se garantir que os casos selecionados para a cirurgia estejam, de fato, preparados psicologicamente para a mesma. No caso de pacientes adultos, o trabalho de orientação é em geral, realizado diretamente com os mesmos. Com pacientes infantis, os pais devem assumir este processo. Em se tratando de pacientes adolescentes, faz-se necessário salientar que o processo deve incluir outros aspectos e questionamentos. A adolescência é uma etapa particular do desenvolvimento, que ocorre de maneira natural, significando inevitável continuação da infância. É também considerada uma etapa evolutiva do ser humano, sendo que, nesta fase, culmina todo um processo maturativo biopsicossocial do indivíduo, (Magagnin, 1997). De acordo com Aberastury (1981): "As mudanças psicológicas que se produzem neste período, e que são a correlação de mudanças corporais, levam a uma nova relação com os pais e com o mundo." (p. 13). Rosa e Velasco (1994) referem ser habitual que o adolescente não tenha ou não demonstre motivação para superar suas dificuldades pois ele não tem bem claro o que está acontecendo com ele. Devido às mudanças incontroláveis de seu corpo e à reformulação de seu psiquismo, é necessário que uma nova acomodação à realidade seja realizada. A estruturação do esquema corporal na fase da adolescência é na verdade, uma sucessão de "elaboração-relaboração", ou "estruturarreestruturar", num vai-e-vem ziguezagueante de constantes auto-reformulações, como é todo desenvolvimento psicossocial do adolescente, conforme diz Chipkevitch (1987). Durante a infância as modificações progressivas, que acompanham o crescimento, são facilmente integradas na imagem geral que a criança faz de seu próprio corpo; já na revolução ocorrida na adolescência, o ritmo de transformação se acelera bastante e necessita de uma revisão radical da imagem corporal, de acordo com Ajuriaguerra (1980). A questão primeira e fundamental na fase da adolescência é, habituar-se ao novo corpo e só secundariamente à necessidade de definir-se como pessoa. Alguns autores citam que a melhor forma de entender e acompanhar as vivências da adolescência resulta do entendimento dos lutos e perdas que o adolescente precisa elaborar para encontrar a identidade estável que o conduzirá ao mundo adulto. Kalina \& Grynberg (1992) relatam que: "A primeira grande perda diz respeito ao próprio corpo, ... quer queira ou não, o seu corpo está mudando, e o adolescente assume um ar desajeitado e frouxo". (p.20). Esta fase refere-se portanto ao luto pelo corpo infantil perdido, relativo à aceitação da nova configuração corporal, inclusive das modificações no esquema corporal, bem como do conhecimento físico de si mesmo. Segundo Kalina \& Grynberg (1992), o adolescente precisa de algum tempo para compreender e aceitar suas recentes aquisições e novos impulsos.

Assim sendo, pode-se supor as dificuldades pelas quais pode passar um adolescente candidato a Implante Coclear para ajustar-se face à problemática física e emocional e à possibilidade de usar um implante, o qual deixará mais exposta sua deficiência auditiva, já que o processador de fala contém uma parte externa bastante visível (Fig. II). Mangabeira - Albernaz (1995) apontam que os adolescentes apresentam um alto grau de rejeição quanto ao uso de unidades externas grandes, como também, aos fios que as unem ao transmissor externo, e que freqüentemente abandonam o uso do Implante Coclear nesta faixa etária.

Apresenta-se pois como importante, compreender as dificuldades enfrentadas por tais pacientes quando diante da indicação do Implante Coclear, no que se refere às suas 
expectativas, temores, ansiedade e conflitos diante da possibilidade de ouvir melhor e das demandas de readaptação de sua auto-imagem e auto-conceito.

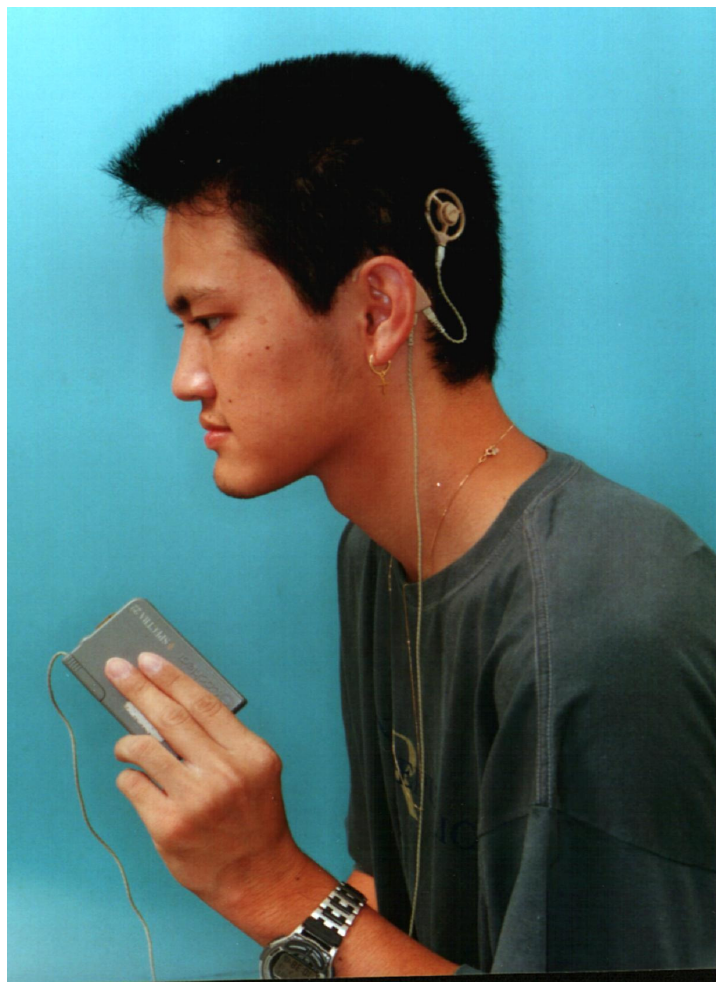

Figura 2. Adolescente demonstrando a parte externa do aparelho de Implante Coclear.

\section{Método}

Este estudo foi desenvolvido no Programa de Implante Coclear do Centro de Pesquisas Audiológicas do H.R.A.C. USP - Campus Bauru. Até o momento, neste programa, foram realizadas 125 cirurgias. Os sujeitos foram 6 pacientes adolescentes, na faixa etária de 13 a 19 anos, 4 homens e 2 mulheres, portadores de deficiência auditiva, que realizaram o Implante Coclear de 7 a 44 meses antes da realização desta pesquisa. Os dados de identificação dos pacientes são apresentados na Tabela I, na parte de resultados. Dados referentes às expectativas, ansiedades/ temores, apresentados nas entrevistas psicológicas no processo avaliativo inicial anterior ao implante, foram coletados dos prontuários dos pacientes. Após o Implante Coclear, nas datas agendadas para acompanhamento de rotina no setor, os pacientes foram submetidos à entrevista psicológica semi-estruturada, elaborada para coleta de dados referentes às atitudes adaptativas na fase de reabilitação bem como avaliações pessoais sobre "ganhos" obtidos com a cirurgia, conforme objetivos deste trabalho. As entrevistas objetivaram coletar informações relativas a: 1) satisfação em relação ao Implante Coclear; 2) adaptação e avaliações subsequentes ao Implante Coclear; 3) expectativas futuras. As entrevistas foram gravadas em áudio, transcritas na íntegra e avaliadas quantitativa e qualitativamente.

\section{Resultados e Discussão}

Os pacientes participantes foram identificados de acordo com as categorias: sexo, idade atual, idade na época da cirurgia, grau de instrução, etiologia da deficiência auditiva, tempo de uso e tipo de aparelho implantado, conforme Tabela I. Os pacientes situaram-se na faixa etária de 13 a 19 anos, todos no $1^{\circ}$ grau de escolaridade, com variadas etiologias de deficiência auditiva, com tempo de uso do Implante Coclear variando de 7 a 44 meses e com tipos de aparelhos similares.

Quanto às expectativas iniciais (antes da orientação pré-cirúrgica), pode-se constatar que a maioria dos pacientes pretendia "ouvir melhor" ou o "mínimo possível" (4 pacientes), sendo que um esperava "ouvir novamente como antes" e um desejava que o Implante Coclear tornasse sua "vida mais feliz". Considerando o apontado na literatura, Aplin (1993) afirma que alguns indivíduos podem esperar um retorno súbito ou agudo da audição após o Implante Coclear, tornando difícil sua adaptação e a obtenção de benefícios por muito tempo após 
o implante. Neste sentido, as expectativas apresentadas pelo sujeitos 2 e 3 (Tabela II), podem ser interpretadas como "pouco realísticas", visto que o Implante Coclear não permite o retorno da audição aos níveis anteriores à perda auditiva, o mesmo ocorrendo com a expectativa de "felicidade". A orientação pré-operatória faz-se necessária, para evitar que os futuros implantados não mantenham expectativas inapropriadas, acreditando que um implante poderá fazê-las pessoas ouvintes conforme diz Booth (1995).

As expectativas apresentadas pósorientação sobre o que era o Implante Coclear, demonstrou que houve modificação nos tipos de expectativas comparadas às apresentadas pelos pacientes no início do processo. Em relação ao conhecimento sobre o Implante Coclear, verificou-se que: metade dos pacientes relatou estar mais consciente sobre o implante e aos possíveis resultados; alguns referiram mais segurança e outros, preocupação com a cirurgia. Houve também os que apontaram a possibilidade do Implante Coclear não dar resultado. Metade dos pacientes enfocou necessidade de se esforçar para usar o aparelho, sendo que alguns apontaram que poderiam apresentar algum tipo de dificuldade para se adaptar (Tabela II).

Pode-se considerar a ocorrência de certa "frustração" com relação às informações sobre a cirurgia, processador de fala e possíveis resultados após a orientação recebida. Metade dos sujeitos referiu acreditar que fosse "diferente", sendo que dois dos pacientes tinham expectativas iniciais consideradas "realistas" e um considerada "irrealista" (paciente $\mathrm{n}^{\circ}$ 6) que esperava que sua "vida se tornasse mais feliz". A literatura aponta que pacientes submetidos a procedimentos cirúrgicos apresentam importantes aspectos psicológicos diante das fantasias, expectativas e ansiedades desencadeadas, o que pode comprometer sua recuperação, conforme diz Sebastiani (1995). Quanto ao processador de fala (componente externo do Implante Coclear),

Tabela 1. Dados de identificação dos pacientes.

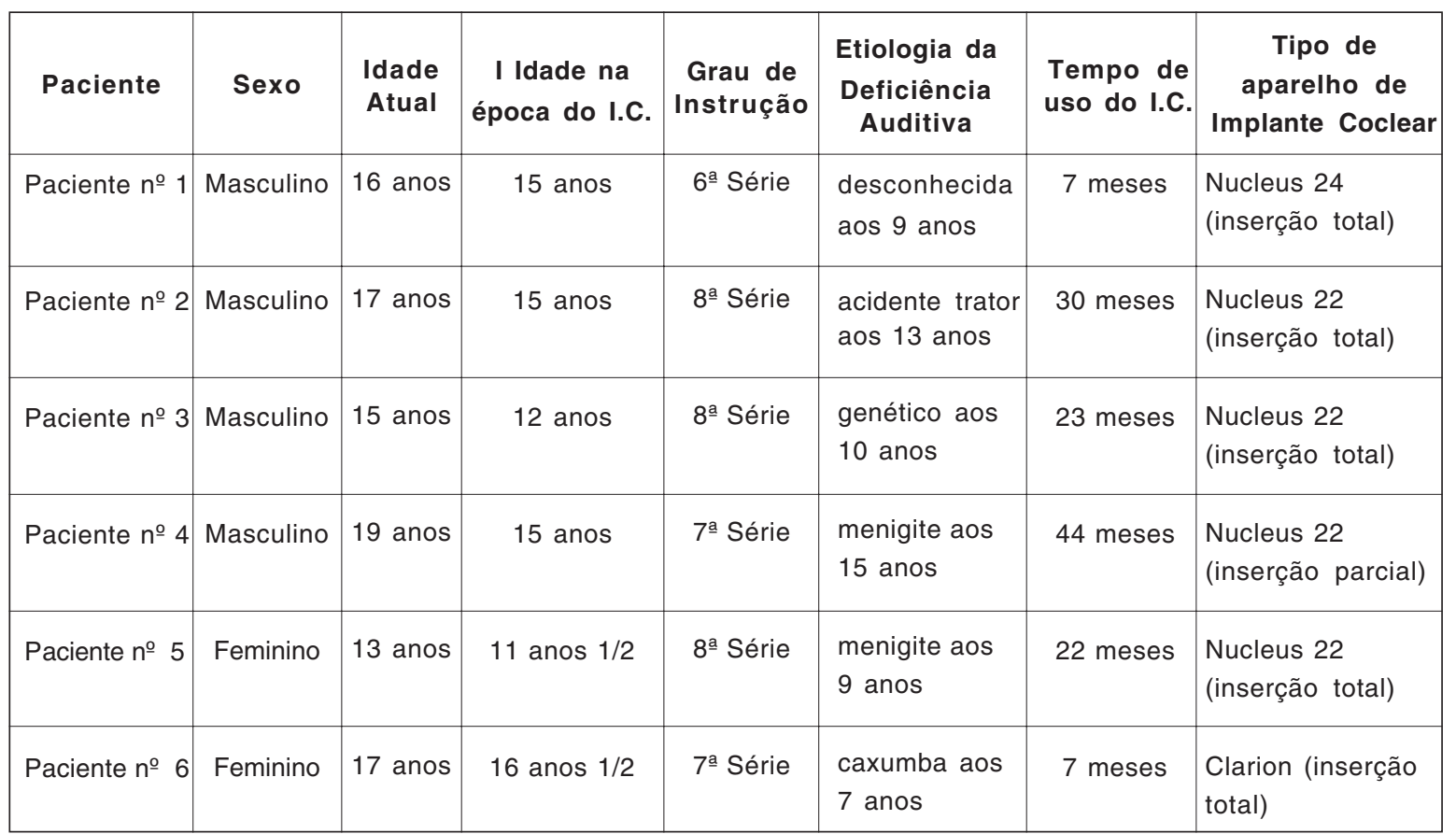

Obs.: Inserção refere-se ao número de eletrodos implantados dentro da cóclea. 
Tabela 2. Comparação entre expectativas iniciais x expectativas pós-orientações.

\begin{tabular}{|c|c|c|}
\hline \multirow[t]{2}{*}{ Paciente } & \multirow{2}{*}{$\begin{array}{l}\text { Expectativas } \\
\text { Inicias }\end{array}$} & Expectativas Pós Orientações sobre I.C. \\
\hline & & Coletados dos prontuários dos pacientes \\
\hline Paciente $\mathrm{n}^{\circ} 1$ & $\begin{array}{l}\text { Ouvir o mínimo } \\
\text { que seja possível }\end{array}$ & $\begin{array}{l}\text { Ouvir melhor, não gostou e está preocupado com a estética do aparelho, pensava } \\
\text { que o I.C. fosse diferente, disse estar consciente sobre o I.C., acredita que no } \\
\text { início será difícil usar o I.C., esforçará para usar o aparelho, acredita na } \\
\text { possibilidade de ouvir novamente, acredita na possibilidade de ouvir sons, } \\
\text { acredita que escutará música. }\end{array}$ \\
\hline Paciente $n^{\circ} 2$ & $\begin{array}{l}\text { Ouvir novamente } \\
\text { como era antes }\end{array}$ & $\begin{array}{l}\text { Ouvir novamente como era antes, não precisará mais fazer LOF, conseguirá } \\
\text { escutar as pessoas perfeitamente, não terá problema algum em relação ao I.C., } \\
\text { poderá o I.C. não dar resultado, acredita que conseguirá escutar música. }\end{array}$ \\
\hline Paciente $n^{\circ} 3$ & Ouvir melhor & $\begin{array}{l}\text { Ouvir melhor, não gostou e está preocupado com a estética do aparelho, tem } \\
\text { preocupações quanto a cirurgia, conseguirá escutar as pessoas perfeitamente, } \\
\text { não terá problema algum em relação ao I.C., poderá o I.C. não dar resultado. }\end{array}$ \\
\hline Paciente $n^{\circ} 4$ & Ouvir melhor & $\begin{array}{l}\text { Ouvir o mínimo possível, não gostou e está preocupado com a estética do } \\
\text { aparelho, disse estar mais consciente sobre o I.C., acredita na possibilidade de } \\
\text { ouvir novamente, acredita na possibilidade de ouvir sons, acredita que conseguirá } \\
\text { escutar música, apresentou altas expectativas sobre o I.C.. }\end{array}$ \\
\hline Paciente $\mathrm{n}^{\circ} 5$ & Ouvir melhor & $\begin{array}{l}\text { Ouvir melhor, não gostou e está preocupado com a estética do aparelho, conseguirá } \\
\text { falar ao telefone, pensava que o implante fosse diferente, disse estar mais } \\
\text { seguro quanto ao I.C., acredita que no início será difícil usar o I.C., esforçará } \\
\text { para usar o aparelho. }\end{array}$ \\
\hline Paciente $n^{\circ} 6$ & $\begin{array}{l}\text { Após o } \\
\text { tratamento } \\
\text { espera que sua } \\
\text { vida torne-se } \\
\text { mais feliz }\end{array}$ & $\begin{array}{l}\text { Após tratamento espera que a sua vida torne-se mais feliz, não gostou e está } \\
\text { preocupado com a estética do aparelho, pensava que o I.C. fosse diferente, } \\
\text { disse estar mais consciente sobre o I.C., esforçará para usar o aparelho, } \\
\text { acredita na possibilidade de escutar novamente, conseguirá escutar as pessoas } \\
\text { perfeitamente, não conseguirá arrumar namorado devido a estética do I.C., } \\
\text { acredita que o I.C. não resolverá sua vida. }\end{array}$ \\
\hline
\end{tabular}

5 pacientes apontaram o aspecto estético como fonte de preocupação e incômodo. Observa-se que o paciente no 6 referiu que "teria dificuldade em conseguir arrumar namorado devido à parte externa do aparelho", denotando preocupação importante na fase da adolescência, quando o corpo deve ser comparado ao dos outros e deve corresponder, até certo ponto, a certas concepções sociais, de acordo com Ajuriaguerra (1980). A preocupação pelo aspecto estético do aparelho pode mobilizar sentimentos de desigualdade de implantados com relação as pessoas ouvintes. Importante observar que o único paciente que não referiu preocupação e/ou incômodo com a parte estética do Implante Coclear foi o paciente $\mathrm{n}^{\circ} 2$ e este havia apresentado expectativas iniciais consideradas "irreais", ("ouvir novamente como antes"), parcialmente mantidas após orientação. No que diz respeito aos resultados esperados com a cirurgia, verificou-se que dois pacientes consideraram a possibilidade do Implante Coclear não dar resultado, sendo que um deles havia apresentado expectativa inicial considerada "real" ("ouvir melhor") e o outro expectativa considerada "irreal" ("ouvir como antes").

Verifica-se que, após orientação pré-cirúrgica, houve manutenção de expectativas altamente positivas entre os pacientes, apesar dos mesmos verbalizarem estarem "mais conscientes" sobre a realidade do Implante Coclear. Conforme Aiub (1995), Cavalcanti 
(1994) e Ferrari (1995) os esclarecimentos pré-cirúrgicos diminuem a ansiedade, possibilitando uma visão mais realista $e$ consciente frente à cirurgia, tornando o paciente mais participativo no processo de recuperação.

Metade dos pacientes estudados acreditou poder voltar a ouvir música e escutar as pessoas perfeitamente. Houve referência quanto à possibilidade de vir a falar ao telefone e não mais haver a necessidade de fazerem a leitura oro facial. Desta forma, as altas expectativas continuaram presentes no discurso verbal dos pacientes contradizendose com o conhecimento formal sobre a cirurgia e suas possibilidades. No entanto, também surgiram preocupações "realistas" quanto a possíveis dificuldades de adaptação posterior ou dificuldades estéticas com o uso do aparelho. Estes dados sugerem que um programa de orientação cuidadoso e o aconselhamento pré-operatório é essencial para assegurar aos pacientes, e não só à família, expectativas apropriadas, compreensão adequada e motivação suficiente para querer realizar o Implante Coclear e aproveitar seus resultados, conforme relata Booth (1995).

Ao serem questionados, após o Implante Coclear, sobre o grau de satisfação que o aparelho trouxe para suas vidas, todos os pacientes afirmaram sua satisfação argumentando que o aparelho ajudava muito na audição, que suas vidas transformaram-se para melhor e que estavam muito felizes. Quanto à correspondência destes resultados com as expectativas prévias ao implante, metade disse que pensava que seria melhor, $\mathrm{e}$ os outros disseram que o resultado foi melhor do que imaginavam. Embora inicialmente todos os pacientes houvessem referido algum tipo de conhecimento sobre o Implante Coclear, percebeu-se que aqueles que disseram que $o$ resultado poderia ser melhor foram os que acreditavam que poderiam "escutar música" $e$ "escutar as pessoas perfeitamente" ("altas expectativas"). Pacientes, que relataram que o resultado foi melhor do que imaginavam, foram os que disseram no início estarem conscientes e mais seguros com relação ao implante, referindo-sea possíveis dificuldades e necessidade de esforço para adaptação ou ainda a possibilidade de que o implante não desse resultado. Verifica-se que dois pacientes esperavam que os resultados obtidos melhorassem ainda mais, ambos com tempo de 7 meses de uso do aparelho (portanto, com possibilidades de obterem outros ganhos).

Quanto ao levantamento das condições de adaptação emocional, metade dos pacientes relatou "não ter vergonha" de usar o aparelho e não se importar com a "curiosidade" das pessoas quanto ao Implante Coclear, relatando mostrar o funcionamento do aparelho. Dois desses pacientes haviam se referido anteriormente (expectativas pré-cirúrgicas) preocupação e descontentamento com o aspecto estético com o uso do aparelho. Neste sentido, tais resultados indicam que ocorreu modificação no que se esperava e no que se obteve de forma positiva, apontando para uma adaptação ao aspecto estético. Os demais pacientes demonstraram certa contradição em seus relatos: o paciente $\mathrm{n}$ - 1 relatou não sentir vergonha em usar o Implante Coclear, porém, "não gostava" e "não entrava em detalhes" quando as pessoas Ihe perguntavam sobre $o$ aparelho. Outros dois pacientes, embora tivessem referido certa "vergonha" em usar o aparelho, às vezes, não se importavam de mostrar e explicar para as pessoas quando eram questionados. Estes três pacientes tinham em suas expectativas prévias uma indicação de preocupação e descontentamento em relação à parte externa do aparelho. Após a cirurgia estes pacientes continuaram incomodados quanto ao aspecto estético, confirmando a importância da imagem corporal neste momento de vida. A vivência emocional do adolescente deve ser pesquisada, permitindo o trabalho com suas ansiedades, fantasias e expectativas, explorando o efeito da surdez sobre a sua auto-imagem e esquema 
corporal, considerando as repercussões destes fatores em sua dinâmica pessoal.

Quanto às atividades antes e após o implante, metade dos pacientes relatou continuar realizando todas as atividades de que gostava. Dois pacientes informaram que precisaram parar com os esportes violentos, demonstrando consciência da fragilidade do aparelho e realização de ajustes às condições atuais. Com relação ao acompanhamento fonoterápico, quatro pacientes disseram não estar realizando. Os dois pacientes que haviam realizado o Implante Coclear mais recentemente estavam empenhados em buscar terapia fonoaudiológica visando melhorar seus resultados pessoais.

Quando questionados sobre se aconselhariam outras pessoas a realizar este implante, $100 \%$ dos pacientes responderam que sim. Todos, com exceção do paciente $\mathrm{n}^{\circ}$ 1 , disseram que se necessário, realizariam tudo novamente para voltar a ouvir. O paciente no 1 era o único com acompanhamento fonoaudiológico. Havia parado com esportes violentos após o implante, não soube apontar pontos positivos quanto ao Implante Cocleare respondeu que pensaria bastante, caso tivesse que fazer tudo novamente, considerando o esforço que o implantado tem que realizar para obter bons resultados. Aplin (1993) coloca a necessidade de se acompanhar os pacientes implantados em intervalos regulares, para monitorar seu estado psicológico e melhorar seu funcionamento, dada a necessidade de se assegurar que os pacientes não se tornem super ansiosos sobre o seu progresso ou super cansados ao trabalhar para melhorar o uso do implante. Um Implante Coclear tem importantes implicações psicológicas para a vida dos implantados e suas famílias. Benefícios psicológicos freqüentemente apontados pelos implantados são os de se sentirem menos isolados e mais seguros em situações sociais.

Quanto à existência de pontos negativos com o uso do Implante Coclear, apenas um paciente negou sua existência. Os demais consideraram a existência de pontos negativos. Dois pacientes relacionaram o custo do seguro e o cuidado que o aparelho exige; um paciente mencionou o funcionamento do Implante Coclear, citando dificuldades para ouvir na presença de muito barulho e dois referiram-se ao incômodo quanto ao aspecto estético com o uso do aparelho. Ao ser questionado sobre a suposta possibilidade do Implante Coclear parar de funcionar, o paciente no 1 não soube responder como seria está situação para ele. Os demais apontaram que seria muito ruim e difícil pois deixariam de fazer muitas coisas. Os dados apresentados evidenciam que a maioria desta amostra (5 pacientes) relacionou aspectos positivos e negativos sobre o implante, sendo o aspecto estético o item gerador de maior incômodo.

Quanto às expectativas de futuro, todos os pacientes mencionaram que ainda esperavam melhoras nos resultados, sendo que a maioria percebia que o aparelho estava melhorando. O paciente $\mathrm{n}^{\circ} 1$ mostrou-se contraditório, referindo-se que esperava melhorar a qualidade do som, e posteriormente, relatando que não precisaria que seu Implante Coclear melhorasse em nada. A maioria dos pacientes responderam que a cada novo programa instalado no aparelho ocorreriam melhoras. O paciente $\mathrm{n} \circ 2$ referiu que os resultados poderiam ser melhores, caso houvesse a possibilidade de acionar todos os eletrodos. O paciente $\mathrm{n}^{\circ} 6$ esperava a possibilidade de que a voz que se escuta através do aparelho fosse mais real. O paciente $\mathrm{n}$ 3 relatou que sentia melhoras a cada novo programa implantado, que não considerava ter que melhorar mais nada quanto aos ganhos com o implante e que o resultado obtido foi melhor do que ele imaginava, sendo o paciente que mais referiu ganhos com a cirurgia.

Quanto ao que os pacientes poderiam/ precisariam fazer para melhorar seus resultados, as respostas apontaram: necessidade de fazer fono e treino para escutar 
mais; necessidade de usar o Implante Coclear e realizar o acompanhamento com a equipe do Centro de Pesquisas Audiológicas; bem como "não sentir tanta vergonha em usar o aparelho". A maioria dos pacientes pareceu reconhecer a importância de sua participação no processo de adaptação pós-cirúrgico para a melhoria dos resultados. A questão estética mostrouse muito importante para o paciente $n^{\circ} 5$, que foi o mais jovem da amostra (13 anos de idade), o que pode sugerir maiores dificuldades de adaptação devido à questão da auto-imagem em desenvolvimento e transformação.

Em geral, os pacientes desta amostra revelaram coerência entre as respostas dadas aos diferentes itens. O paciente de $\mathrm{n}$ 1 mostrouse contraditório nas respostas, parecendo não discernir satisfação e/ou descontentamento quanto à avaliação pessoal dos resultados do Implante Coclear. Este, no entanto, foi o paciente que mais se mostrou empenhado no processo de adaptação, tendo sido o único a apresentar expectativas iniciais de "ouvir o mínimo possível" com o implante (não tendo ficado esclarecido o significado da palavra "o mínimo" neste contexto para este sujeito).

Os resultados obtidos no estudo indicaram que houve similaridade entre os tipos de expectativas, ansiedades e temores dos pacientes prévios à cirurgia e suas avaliações subsequentes ao Implante Coclear. Todos os pacientes da amostra apresentaram expectativas prévias positivas, mais ou menos "realistas" quanto aos resultados possíveis com o Implante e as confirmaram posteriormente.

A orientação pré-cirúrgica demonstrou-se importante procedimento de adequação das expectativas prévias, resultando, em alguns casos, em aumento de "cuidado" com a cirurgia e seus efeitos. Com exceção de um paciente, todos referiram alguma preocupação prévia quanto ao aspecto estético do aparelho auditivo, sendo que todos, após o implante, demonstraram algum tipo de incômodo com relação à estética, em maior ou menor intensidade.

Levando-se em conta o tempo de uso do implante, que variou entre 7 à 44 meses após a cirurgia, verificou-se que neste estudo o tempo não pareceu interferir na avaliação dos resultados posteriores. As respostas obtidas mantiveram-se constantes para a maioria destes pacientes, podendo indicar tendência de que expectativas de resultados melhores acompanhem melhores avaliações posteriores quanto aos ganhos com o Implante Coclear. As alterações das expectativas iniciais observadas após orientações pré-implante, (os pacientes verbalizaram estar mais "conscientes" sobre o aparelho, indicando um certo nível de "frustração" quanto a alguns aspecto do Implante Coclear) indicaram que as expectativas prévias poderiam estar permeadas de "fantasias" que poderiam prejudicar avaliação de "ganhos" com a cirurgia.

\section{CONCLUSÃO}

Os resultados obtidos indicaram similariedade entre expectativas, ansiedade e temores dos candidatos ao Implante Coclear averiguados antes da realização da cirurgia e suas avaliações quanto aos ganhos obtidos com o implante após sua realização. Indicam também a efetividade da orientação pré-cirúrgica na promoção de algumas adequações entre expectativas dos pacientes e possibilidades reais com a realização do implante. Entretanto, tal orientação verbal não se mostrou suficiente, em todos os casos, para evitar frustração e avaliações negativas, após algum tempo de uso do Implante Coclear, o que foi possível clarificar por meio do acompanhamento psicológico subseqüente.

Tais resultados permitem sugerir a relevância da orientação pré-cirúrgica e do acompanhamento psicológico destes pacientes no pré e pós-cirúrgico, especialmente tratando-se de adolescentes que terão 
modificados sua estética corporal com o uso do aparelho auditivo.

O acompanhamento psicológico pode minimizar dificuldades de adaptação relacionadas à auto-imagem, facilitando as adequações necessárias entre expectativas prévias e avaliações de resultados obtidos com a cirurgia de Implante Coclear, o que corresponde ao encontrado na literatura desta área.

Sugerem-se estudos com amostras maiores de pacientes e/ou com grupo-controle, de modo a permitir outros níveis de análises.

\section{REFERÊNCIAS BIBLIOGRÁFICAS}

ABERASTURY, A., Knobel, M. (1992). Adolescência normal. Porto Alegre: Artes Médicas.

AIUB, A.L.C. et al. (1995). Ansiedade em pacientes cardíacos pré-cirúrgico. Revista Sociedade Cardiologia, 5 (6): 6-8.

AJURIAGUERRA, J. (1980). Manual de psiquiatria. Rio de Janeiro: Masson do Brasil.

APLIN, Y. (1993). Psychological assessment of multi-channel cochlear implant patients. Journal of Laryngology and Otology, 107: 298-304.

BEVILACQUA, M.C. Implante Coclear multicanal: uma alternativa na habilitação de crianças surdas. Bauru, 1998. Tese (livre docecência em fonoaudiologia) - Faculdade de Odontologia de Bauru, Universidade de São Paulo.

BOOTH, C.L., et. al. (1995). Involving the older child in the cochlear implant decision-making process. Ann. Otol. Rhinol Laryngol. Suppl., 166: 207-208.

CAVALCANTI, M.C.T. (1994). Aspectos emocionais no pré-operatório em amputação de membros. Jornal Brasileiro de Psiquiatria,43 (3): 159-161.
CHIPKEVITCH, E.O. (1987). O adolescente e o corpo. Pediatria Moderna, 22 (6): 231-237.

COOPER, H. (1991). Cochlear implants: a pratical guide. London: Whurr Publishers.

COOPER, H. (1995). Implantes cocleares. In: Ballantyne, J. Surdez. Porto Alegre: Artes Médicas, pp. 277-285.

COSTA FILHO, O. A., Bevilacqua, M.C. Programa de implante coclear. Disponível: site Hospital de Reabilitação de Anomalias Craniofaciais. URL: http:// www.centrinho.usp.br. consultado em 19 de outubro de 1999.

FERRARI, B. (1985). Preparação psicológica do paciente cirúrgico. Rev. Inf. Cienc. Cult. Doutora, 2 (7): 47-50.

KALINA, E., Grynberg, H. (1992). Aos pais de adolescentes. Rio de Janeiro: Francisco Alves.

MAGAGNIN, C. et. al. (1997). Autoconceito e adaptação do adolescente. Alethéia, 6: 5-23.

MANGABEIRA-ALBERNAZ, P.L. (1995). Implantes cocleares: parte 1. Revista Brasileira de Medicina, 2 (6): 415-423.

NEME, C.M.B. (1991). Abandono prematuro da psicoterapia: um estudo exploratório comparando motivos alegados por pacientes que abandonaram ou não a psicoterapia. Campinas. Dissertação (Mestrado em Psicologia Clínica) Pontifícia Universidade Católica de Campinas: 318.

RIBEIRO, S.F.M. et al. (1995). Avaliação psicológica pré-operatória de pacientes submetidas a ritidoplastia. Revista Hospital Clínicas Faculdade Medicina São Paulo, 50: 17-21.

ROSA, L.W., Velasco, J.L.P. (1994). A aliança terapêutica na psicoterapia de adolescentes. In: Granã, R.B. Técnica psicoterápica na adolescência. Porto Alegre: Artes Médicas, pp. 67-87. 
SEBASTIANI, R.W. (1995) Atendimento psicológico no centro de terapia intensiva. In: Angerami, V.A. (org). Psicologia Hospitalar: teoria e prática. São Paulo: Pioneira, pp. 29-71.
YAMADA, M. O., Bevilacqua, M.C., Costa Filho, O. A. (1999). A intervenção do psicólogo no pré e pós-operatório do programa de Implante Coclear. Pediatria Moderna, 35 (3): 01. 